\title{
Microbial Inoculation for Productivity Improvements and Potential Biological Control in Sugar Beet Crops
}

\author{
Gonzalo Sacristán-Pérez-Minayo ${ }^{1 *}$, Domingo Javier López-Robles², Carlos Rad² and \\ Luis Miranda-Barroso ${ }^{3}$
}

\begin{abstract}
${ }^{1}$ Microbiology Section, Faculty of Sciences, University of Burgos, Burgos, Spain, ${ }^{2}$ Edaphology and Agricultural Sciences Section, Faculty of Sciences, University of Burgos, Burgos, Spain, ${ }^{3}$ Sustainable Agriculture Department, Syngenta-Spain, Madrid, Spain
\end{abstract}

\section{OPEN ACCESS}

Edited by: loannis Stringlis,

Utrecht University, Netherlands

Reviewed by:

Claire Prigent-Combaret, UMR 5557 Ecologie Microbienne

(LEM), France

Dilfuza Egamberdieva, Leibniz Center for Agricultural Landscape Research (ZALF),

Germany

*Correspondence: Gonzalo Sacristán-Pérez-Minayo gsacristan@ubu.es

Specialty section: This article was submitted to Plant Symbiotic Interactions, a section of the journal

Frontiers in Plant Science

Received: 10 September 2020 Accepted: 04 December 2020 Published: 22 December 2020

Citation:

Sacristán-Pérez-Minayo G, López-Robles DJ, Rad C and Miranda-Barroso L (2020) Microbial Inoculation for Productivity Improvements and Potential Biological Control in Sugar Beet Crops. Front. Plant Sci. 11:604898. doi: 10.3389/fpls.2020.604898
Used mainly for sucrose production, sugar beet is one of the most important crops in Castilla y León (Spain). Several studies have demonstrated the benefits of microorganisms in different crop management programs, among which Plant Growth Promoting Rhizobacteria (PGPR). This research aims to assess the beneficial effects of two PGPRs strains (Pseudomonas fluorescens PfO-1 and Pseudomonas chlororaphis CECT 462) on sugar beet (Beta vulgaris) production. Three treatments: a PGPRs co-inoculation assay of untreated seeds without any chemical treatment (TB), a conventional treatment with commercial seeds and fungicide application (TT); and a control with seeds without protective coating, bacterial inoculation and chemical treatment (ST). The efficacy of PGPRs inoculation on sugar beet production was determined measuring periodically the photosynthetic status of plants, and the final yield and quality of tubers. Aerial and root plant biomass, maximum beet perimeter, polarization, and sugar values of the sugar beet plants inoculated with PGPRs showed higher values and significant differences to sugar beet subjected to other treatments. We could see that PGPRs inoculation (TB treatment) produced significant differences in the quantum yield of PSII (ФPSII). TB showed the highest value for $\Phi P S I l$ and the NPQ (nonphotochemical quenching), the lowest value, even though the PSII (maximum quantum yield of photosystem II) was very similar in all treatments. The two assayed PGPR strains triggered a significant increase in sugar beet production yield and quality. PGPRs inoculation techniques could be used in different crops and they could be applied as biofertilizers, improving the agricultural production.

Keywords: integrated crop management, PGPR, sugar beet, photosynthesis parameters, sucrose

\section{INTRODUCTION}

Sugar beet (Beta vulgaris L. var. saccharifera) is an important root crop in moderate climates and the main source of sugar (Dohm et al., 2014). The worldwide cropping area covers over approximately 4.5 million $\mathrm{Ha}$, with roughly $70 \%$ of sugar beet production in Europe (FAOSTAT, 2019). Annual world sucrose production stands 175.6 million tons in 2017, of which $28 \%$ is extracted from sugar 
beet (Beta vulgaris L.), and the remainder from sugar cane OECD/FAO (2020). Sugar production in 2018 was approximately $2,870,907$ tons (FAOSTAT, 2019). In Spain, sugar beet cultivation is reported to cover about $53,000 \mathrm{Ha}$. The present research was conducted in the region of Castilla y León, where sugar beet is one of the most important industrial crops, providing over 50\% of all Spanish beet sugar. Sugar beet crop profitability is valued in terms of sugar production, which basically refers to its sucrose purity factor, as sucrose content is made up of more than $99.5 \%$ in the final white crystalline sugar (Pan et al., 2015).

Several research studies have noted the importance of soil microbiome on plant health, in particular in sugar beet crops (Berendsen et al., 2012; Bakker et al., 2013, 2020; Weijuan et al., 2020; Wolfgang et al., 2020). In fact because the genome and breeding history is known, sugar beet is an interesting model crop for microbiome studies (Zachow et al., 2008; Mendes et al., 2011; Würschum et al., 2013; Dohm et al., 2014; Kusstatscher et al., 2019a,b). Hiltner (1904) established the importance of the rhizosphere microbiome for growth promotion in crops and omics technologies allow in-depth analysis, nowadays (Mendes et al., 2011; Raaijmakers and Mazzola, 2016).

Bacteria with multiple beneficial traits can be advantageous in commercial agriculture and are relevant to the bio-economy (Backer et al., 2018). Recently, research on Plant Growth Promoting Rhizobacteria (PGPR) for crop improvements are gaining prominence and thousands of research works have been published so far (Compant et al., 2005; Mia et al., 2010; Backer et al., 2018). The term PGPR was first defined by Kloepper et al. (1980) in the 1980s, later Compant et al. (2005) subsequently described PGPR as microorganisms from the rhizosphere that can positively influence plant growth and plant health. These PGPRs have ability to protect the plants from drought, salts and heavy metal stresses and play significant role in the plant growth promotion, yields, nutrient acquisition and as well as minimizing the use of chemical fertilizers (Kumar et al., 2019). In particular, PGPRs could promote directly plant growth by various mechanisms, including: (i) the production of phytohormomes such as auxins, cytokinins and gibberellins (Santner et al., 2009); (ii) the production of plant growth promoting (PGP) substances such as indole-3-acetic acid (IAA) and/or siderophores which can provide soluble iron to plants (Scher and Baker, 1982); (iii) the increase of the solubilization of phosphorus and other trace element for plant uptake (Gyaneshwar et al., 2002); (iv) the supply of nutrients to plants, by asymbiotic nitrogen fixation (Doberein and Campelo, 1971) and v) the secretion of enzymes that can modulate plant growth and development, such as reducing ethylene level by synthesis of 1-aminocyclopropane-1-carboxylic acid (ACC) (Yang and Hoffman, 1984; Penrose et al., 2001). The use of PGPRs as biological control agents have been found effective and are being increasingly applied in the field (Pooja et al., 2019). Indirectly, some PGPRs are able to reduce the disease development in plant system by various mechanisms that include among others: production of antimicrobial metabolites, volatile compounds and induced systemic resistance (ISR) (Hassani et al., 2018; Stringlis et al., 2018).

Sugar beet is known to be affected by several pathogens, including bacteria, fungi, viruses and nematodes. Cercospora beticola Sacc. and Erysiphe betae (Vañha) Weltz are the causative agents of Cercospora Leaf Spot (CLS) and powdery mildew, respectively, and they are the most damaging foliar diseases for sugar beet crops (Jay et al., 2020). CLS occurs in sugar beet-growing areas worldwide and can lead to reductions in recoverable sucrose of $30-48 \%$ (Khan et al., 2001). CLS is a polycyclic disease whose severity depends on weather conditions C. beticola's full disease cycle can occur in as few as 10 days under suitable climatic conditions of high relative humidity and high temperatures, thus resulting in multiple infection cycles in each growing season. Fungus conidia infect leaves, resulting in the appearance of millimeter-scale brown round spots. These necrotic spots then expand and coalesce, eventually defoliating the whole plant and requiring new leaves to grow. Beet powdery mildew is also another worldwide fungal disease of sugar beet. Powdery mildew is characterized by a white dust-like mycelium that develops over the leaf surface. Heavily infected tissues develop chlorosis and suffer early senescence, with infection being especially damaging in areas with arid climates, such as in Mediterranean countries (Fernández-Aparicio et al., 2009). Fungal diseases incidence can occur on sugar beet in one season, consecutively or simultaneously, and outbreaks can result in a significant loss of the crop in years with high disease pressure (Heick et al., 2020). The severity and frequency of fungal disease attacks vary considerably every year, depending on factors as weather conditions, microclimate, and agronomic practices (Heick et al., 2020). The traditional treatment for these fungal diseases involves prevention, in other words treatment with highly fungicidal phytosanitary products may be effective in controlling the development of both pathogens incidence. However, a significant reduction of the use of fungicides is highly desired since, some of them, affect the environment while being expensive (Van Zwieten et al., 2004).

There is therefore a need for complementary agricultural practices, such as the use of microorganism-based biological control methods (Compant et al., 2005; Naureen et al., 2009). Pseudomonas and Bacillus are the most commonly described genera possessing plant growth promoting activities (Munees and Mohammad, 2011). Pseudomonas are frequently found across all life stages of sugar beet and that several strains with promising biocontrol potential were found in sugar beet endosphere (Zachow et al., 2008, 2010).

Pseudomonas chlororaphis is capable of promoting the growth of plants such as wheat and corn (Agaras et al., 2020) or millet (Niu et al., 2018). It has been possible to verify the protective capacity against different pathogens such as fungi (Rhizoctonia solani) where it induced the plant to increase the expression of certain genes that influenced its protection (Kamou et al., 2020). Indirectly, Pseudomonas fluorescens Pf0-1 stimulates plant growth by protecting it from attack by Pythium ultimum, Gaeumannomyces graminis var. tritici, and Fusarium oxysporum, in addition to the motility and degree of chemotaxis that it possesses, which are essential properties in the colonization of vegetable roots (Oku et al., 2012).

In the present work, we evaluated the successive application of a mixed PGPRs culture (Pseudomonas fluorescens Pf0-1 and $P$. chlororaphis CECT 462) on the productivity of sugar beet 
evaluated in terms of production yield and sucrose content, and physiological changes in the whole cycle of the plant. Additionally, we also monitored the biocontrol effects of PGPRs against two fungal pathogens, Cercospora beticola and Erysiphe betae, throughout the sugar beet production cycle.

\section{MATERIALS AND METHODS}

\section{Plant Material and Bacterial Strains}

Seeds of Beta vulgaris var. Turbata, tolerant to the fungal pathogens Cercospora beticola and Erysiphe betae, were provided by Koipesol Semillas, S.A. These commercial seeds have a protective coating containing fungicide and insecticide formulations. The sugar beet standard planting density was 100,000 plants per hectare.

The present research was conducted in the region of Castile and Leon, where sugar beet is one of the most important industrial crops, providing over $50 \%$ of all Spanish beet sugar (Esteban Baselga, 1993). The present experiment was performed in the 2018 sugar beet campaign, from April to November.

In the present experiment, we applied a combination of two PGPRs strains, Pseudomonas fluorescens Pf0-1 and Pseudomonas chlororaphis CECT 462. The first of the Pseudomonas strains was isolated from an agricultural soil in Pampliega $\left(42^{\circ} 12^{\prime} \mathrm{N}\right.$; $3^{\circ} 58^{\prime} \mathrm{W}$; altitude $809 \mathrm{~m}$ asl), Burgos (Spain) (Sacristán PérezMinayo et al., 2011). We used the Fasta Nucleotide Similarity Search Database available from the European Bioinformatics Institute (EMBL-EBI) ${ }^{1}$ and we obtained a percentage of similarity of $100 \%$ and a percentage of identity of $99.107 \%$ compared with Pseudomonas fluorescens Pf0-1 (EMBL: CP000094). Pseudomonas chlororaphis CECT 462 was provided by the Spanish Collection of Type Cultures (CECT - Colección Española de Cultivos Tipo, 2020). To determine the compatibility between PGPR strains, a cross-streak method of inoculation was done checking the appearance of inhibition zones at the intersection of the paired strains (Santiago et al., 2017). The bacterial strains were maintained at $-80^{\circ} \mathrm{C}$ in nutrient broth with $20 \%$ glycerol. Inocula were prepared, separately, by streaking strains at $-80^{\circ} \mathrm{C}$ onto King A medium (Cultimed, Spain), incubating plates at $30^{\circ} \mathrm{C}$ for $24 \mathrm{~h}$. After incubation, the plates were scrapped off into a sterile $10 \mathrm{mM} \mathrm{SO} \mathrm{SO}_{4} \mathrm{Mg}$ buffer at a suspension of $10^{8} \mathrm{CFU} / \mathrm{ml}$. This final suspension contained both PGPR strains and was prepared repeatedly before each PGPRs spraying applications.

\section{Experimental Design}

The present experiment was performed in the 2018 sugar beet campaign, from 8th April to 26th November. The experimental plot occupied $252 \mathrm{~m}^{2}$ (18 $\mathrm{m}$ long and $14 \mathrm{~m}$ wide) of an irrigated field ( $32.30 \mathrm{Ha}$ ) located on the outskirts of Pedrosa del Rey, Valladolid. The site is placed at $706 \mathrm{~m}$ of altitude. Annual mean temperature was $12^{\circ} \mathrm{C}$, minimum temperature $\left(-0.3^{\circ} \mathrm{C}\right)$ was found in January and the maximum $\left(29.4^{\circ} \mathrm{C}\right)$ in July. In relation with frost days, the last frost day of spring was 13rd April and

${ }^{1}$ http://www.ebi.ac.uk/Tools/sss/fasta/nucleotide.html first frost day of autumn was 8th November. Hence, we had 208 free frost days. The mean annual rainfall was $374 \mathrm{~mm}$ with 61 rainfall days per year (ITACYL - Instituto Tecnológico Agrario de Castilla y León, 2019). The field had corn as precedent crop and is classified as LVk Calcaric Luvisol (IUSS Working Group WRB, 2015). Main soil properties are: texture, $\mathrm{pH}, \mathrm{EC}, \mathrm{SOM}$, Total $\mathrm{N}$. The soil $\mathrm{pH}$ and the organic matter content were 8.3 and closely to $2 \%$, respectively. The texture of the soil in the experimental plots was, in general, loamy, except some small area was found as loamy-clayey. The mean clay content was $25.65 \%$. We performed three different treatments in a completely randomized block design: TB, without seed coating, with PGPRs inoculum application and chemical spraying; TT, with seed coating and chemical spraying and without PGPRs inoculum and ST, without seed coating, chemical spraying and PGPRs inoculum. The chemical spraying consisted of a mixture of "Karate King" insecticide $(0.5 \mathrm{Kg} / \mathrm{Ha})$, “Tilt" fungicide ( $1.25 \mathrm{l} / \mathrm{Ha})$ and boron-molybdenum fertilizer $(2.50 \mathrm{l} / \mathrm{Ha})$. Each treatment had four replicates of $2 \times 2 \mathrm{~m}^{2}$ subplots, in which 40 plants were introduced, and with $2 \mathrm{~m}$ interrow spaces between them, to avoid border effect. Irrigation was performed using a central pivot system $\left(30-50 \mathrm{l} / \mathrm{m}^{2}\right.$ per week) throughout the whole production cycle, according local irrigation schedule.

The seeds protective coating was removed in TB and ST treatment, with thorough washing and stirring of seeds in sterile distilled water, with the purpose of check the inoculum effect without the presence of fungicide or herbicides. After coating removing, the seeds in the TB trial were inoculated by immersion for $6 \mathrm{~h}$ at $30^{\circ} \mathrm{C}$ with the mixed culture of PGPR strains, Pseudomonas fluorescens Pf0-1 and Pseudomonas chlororaphis CECT 462. Immediately after sowing, the seeds for the TB replicates were irrigated once with the mixed PGPRs inoculum (1 $\mathrm{ml}$ per seed). The plant leaves in the TB replicates were sprayed six times with the PGPRs suspension $(1,500 \mathrm{ml}$ each sprayed time). Foliar spray application was performed to promote microorganism-plant interactions during the production cycle. The dates of the PGPRs spraying applications were: first PGPRs spraying, 23 May 2018; second PGPRs spraying, 19 June 2018; third PGPRs spraying, 01 July 2018; fourth PGPRs spraying, 31 July 2018; fifth PGPRs spraying, 02 September 2018, and sixth PGPRs spraying, 08 October 2018. The TT subplots were initially irrigated with water and thereafter, sprayed with water and a mixture of insecticide, fungicide and fertilizer, at the same time as the TB treatment. ST subplots were irrigated and sprayed with water six times. The timelines for the three treatments are shown schematically in Supplementary Figure 1.

\section{Sugar Beet: Crop Production Yield and Quality}

At the end of the production cycle (232 days after sowing), 10 plants were harvested per subplot and the following parameters analyzed: sugar content $(\mathrm{kg})$, polarization (\%), corrected sucrose, $\mathrm{N}$-amino, potassium $(\mathrm{K})$ and sodium $(\mathrm{Na})$ content and industrial loss and yield (\%) according to the International Sugar Scale. The total, aerial and root biomass $(\mathrm{kg})$ were also recorded, as well as the root maximum beet perimeter and length. Sucrose content 
was measured by polarization (Schmidt and Haensch Mod. 14220 ), $\mathrm{Na}$ and $\mathrm{K}$ content by flame photometry (Model NAK1 Pacisa), and $\alpha$-amino-nitrogen content ( $\alpha-\mathrm{N})$ according to the Stanek and Pavlas (1934) blue index method, as modified by the Swedish Sugar Company with the values given by the Wieninger and Kubadinow (1973) formula. The corrected sucrose, industrial loss and yield values were also calculated with the Wieninger and Kubadinow formulae.

Soil properties were determined after harvest. In each plot, a composite soil sample was obtained at three different point in the crop row in each subplot using an auger $(\varnothing 5 \mathrm{~cm})$, mixed and placed in labeled bags. Texture, $\mathrm{pH}$, conductivity and organic matter content were then determined using standard methods (MAPA., 1994).

Levels of available phosphorus, exchangeable sodium and magnesium and soluble boron were also determined (Table 1).

\section{Photosynthesis Parameters Measurement}

The photosynthetic status of a plant can be used as an indicator of its physiological status with respect to biostimulation or after a pathogenic attack. Foliar pathogens can cause the reduction of photosynthetic active leaf area, because of the leaf damage and the disturbance of photosynthesis in the remaining or surrounding leaf area (Berger et al., 2004; Robert et al., 2006). For instance, when a CLS disease severity on sugar beet of reached 3-6\%, photosynthesis is reduced (Levall and Bornman, 2000). Thus, photosynthesis was measured in 10 leaves from 10 healthy plants with similar vegetative state in each subplot, 2 days after the third PGPRs inoculation (03 July 2018). This date was chosen because the physiological status of the plants was at the highest stage of sugar production.

A portable FMS2 fluorimeter (Fluorescence Monitoring System, Hansatech, Norfolk, United Kingdom) was used to measure fluorescence emission of chlorophyll in leaves previously adapted to darkness, to determine the efficiency of photosynthesis and to diagnose the presence of stress factors that decrease it (Krause and Weis, 1991; Baker, 2008). It also has the advantage of being a non-destructive technique. Two consecutive measurements were performed on the same leaf. The first one, corresponding to minimal fluorescence (Fo), is taken with the leaf adapted to dark conditions using a clamp for $20 \mathrm{~min}$; thereafter the measure was repeated after a saturating light pulse, corresponding to the maximum fluorescence $(\mathrm{Fm})$. With these two parameters, we calculated the maximum quantum yield of photosystem II (PSII) that indicates the maximum amount of energy that PSII could potentially expend in photochemical processes, which is calculated as $\mathrm{Fv} / \mathrm{Fm}$, where $\mathrm{Fv}$ is variable fluorescence $=\mathrm{Fm}-$ Fo. In the second step, we measured fluorescence emitted by the leaves adapted to light (Fs), and fluorescence when subjected to a saturating light pulse $\left(\mathrm{Fm}^{\prime}=\right.$ maximum fluorescence measured in a state adapted to light). These parameters allowed us to calculate the quantum yield of PSII (ФPSII), as $\Phi$ PSII $=\left(\mathrm{Fm}^{\prime}-\mathrm{Fs}\right) / \mathrm{Fm}^{\prime}$, and to quantify the proportion of energy absorbed by PSII that is used in photosynthetic electron transport (Genty et al., 1989), which therefore reveals the actual amount of energy that may be used for photochemical processes. Finally, we calculated NPQ (non-photochemical quenching) parameter. It was calculated as $\mathrm{NPQ}=\left(\mathrm{Fm}-\mathrm{Fm}^{\prime}\right) / \mathrm{Fm}^{\prime}$, a parametric indicator of the proportion of energy received that is dissipated as heat and therefore not used for photochemical processes (Ögren and Baker, 1985; Baker, 2008; Rodríguez-Moreno et al., 2008). All data were processed with MODFL2 software.

\section{Determination of Resistance to Plant Pathogens}

The incidence of Cercospora beticola and Erysiphe betae was recorded throughout the production cycle at four timepoints: after third, fifth, and six PGPRs spraying applications and after the final harvest. Visual assessment of diseases was scored on a four-point scale, where $1=0-25 \%$ of the replicated area that was affected, $2=26-50 \%$ of the replicated area that was affected, $3=51-75 \%$, and $4=76-100 \%$, for each fungal pathogen (Supplementary Figure 2).

Infection index was calculated as the percentage of affected plants in each replicate as Index $(\%)=\mathrm{N} / \mathrm{N}_{\mathrm{t}}$, where $\mathrm{N}$ is the number of affected plants in each replicate and $\mathrm{N}_{t}$ is the total number of plants per replicate.

Severity was determined at pathogen assessment-time 2 of the production cycle, the day on which both fungal pathogens reached their highest growth. The severity index was calculated as the percentage of affected leaves on a randomly selected sugar beet plant. The sugar beet plant selected in each replicate was a representative plant of medium size located at the center of the plot. Severity $(\%)=\mathrm{L} / \mathrm{L}_{\mathrm{t}}$, where $\mathrm{L}$ is the number of affected leaves and $L_{t}$ the total number of leaves. The visual assessment was evaluated on all four timepoints, the infection index was evaluated at timepoints 2 and 3 , and the severity index, at timepoints 2 .

\section{Statistical Analysis}

One-way analysis of variance (ANOVA) using treatment as fixed factor was performed after checking for normality and homogeneity of variances with Kolmogorof-Smirnof's and Levene's test, respectively, LSD test was used to calculate significative differences between treatments. These analyses were carried out using STATGRAPHICS Plus 4.0 software. One and two-ways ANOVA was performed to evaluate the differences between treatments in each fungal disease and between sampling days.

\section{RESULTS}

\section{Sugar Beet: Crop Production Yield and Quality}

Percentage plant survival rates per replicate were: 92,96 , and $98 \%$ for the ST, the TB and the TT assays, respectively. The plant populations of the three assays were very similar and there were no significant differences between the ST, the TB, 
TABLE 1 | Soil parameters measured at the end of the sugar beet productive cycle.

\begin{tabular}{|c|c|c|c|c|c|c|c|c|c|}
\hline & Sand (\%) & Silt (\%) & Clay (\%) & Texture & $\mathrm{pH}$ & $\begin{array}{l}\text { Conductivity } \\
\text { (mmhos/cm) }\end{array}$ & $\begin{array}{c}\text { Organic } \\
\text { matter (\%) }\end{array}$ & $\begin{array}{l}\text { Phosphorus, } \\
\text { P (ppm) }\end{array}$ & $\begin{array}{c}\text { Potassium, } \\
\text { K (ppm) }\end{array}$ \\
\hline ST1 & 43.84 & 32 & 24.16 & Loam & 8.3 & 0.44 & 2.05 & 50 & 251 \\
\hline ST2 & 39.84 & 34 & 26.16 & Loam & 8.2 & 0.5 & 1.9 & 51 & 177 \\
\hline ST3 & 49.84 & 24 & 26.16 & Loamy-clay-sand & 8.5 & 0.5 & 1.94 & 49 & 409 \\
\hline ST4 & 49.84 & 28 & 22.16 & Loam & 8.3 & 0.43 & 1.82 & 47 & 265 \\
\hline TB1 & 47.84 & 30 & 22.16 & Loam & 8.3 & 0.84 & 1.74 & 54 & 281 \\
\hline TB2 & 45.84 & 28 & 26.16 & Loam & 8.5 & 0.46 & 1.74 & 50 & 276 \\
\hline TB3 & 43.84 & 32 & 24.16 & Loam & 8.2 & 0.55 & 1.78 & 46 & 283 \\
\hline TB4 & 39.84 & 34 & 26.16 & Loam & 8.3 & 0.48 & 2.32 & 45 & 247 \\
\hline T11 & 39.84 & 34 & 26.16 & Loam & 8.2 & 0.44 & 1.59 & 53 & 276 \\
\hline Т12 & 41.84 & 30 & 28.16 & Loamy-clay & 8.3 & 0.49 & 1.59 & 45 & 246 \\
\hline ТТ3 & 43.84 & 28 & 28.16 & Loamy-clay & 8.3 & 0.47 & 1.86 & 41 & 354 \\
\hline Tा4 & 41.84 & 30 & 28.16 & Loamy-clay & 8.3 & 0.48 & 2.01 & 46 & 355 \\
\hline & \multicolumn{2}{|c|}{ Magnesium, Mg (ppm) } & Carbonates (\%) & Active lime (\%) & \multicolumn{2}{|c|}{ Exchangeable calcium (ppm) } & \multicolumn{2}{|c|}{ Exchangeable sodium (ppm) } & Boron, B (ppm) \\
\hline ST1 & \multicolumn{2}{|l|}{496} & 0.15 & $x$ & \multicolumn{2}{|c|}{$x$} & \multicolumn{2}{|c|}{468} & 0.95 \\
\hline ST2 & \multicolumn{2}{|l|}{583} & 0.23 & $x$ & \multicolumn{2}{|c|}{$x$} & \multicolumn{2}{|c|}{373} & 0.88 \\
\hline ST3 & \multicolumn{2}{|l|}{510} & 0.38 & $x$ & \multicolumn{2}{|c|}{$x$} & \multicolumn{2}{|c|}{495} & 0.95 \\
\hline ST4 & \multicolumn{2}{|l|}{503} & 0.31 & $x$ & \multicolumn{2}{|c|}{$x$} & \multicolumn{2}{|c|}{206} & 0.75 \\
\hline TB1 & \multicolumn{2}{|l|}{523} & 0.31 & $x$ & \multicolumn{2}{|c|}{$x$} & \multicolumn{2}{|c|}{420} & 0.88 \\
\hline TB2 & 542 & & 0.15 & $x$ & & $x$ & & & 0.83 \\
\hline TB3 & 598 & & 0.23 & $x$ & & $x$ & & & 0 \\
\hline TB4 & 561 & & 0.38 & $x$ & & $x$ & & & 0.83 \\
\hline T1 & 501 & & 0.31 & $x$ & & $x$ & & & 0.83 \\
\hline Т12 & 537 & & 0.15 & $x$ & & $x$ & & & 1.2 \\
\hline ТТ3 & 581 & & 0.23 & $x$ & & $x$ & & & 1.13 \\
\hline Tा4 & 630 & & 0.31 & $x$ & & $x$ & & & 1 \\
\hline
\end{tabular}

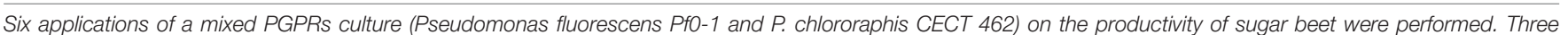

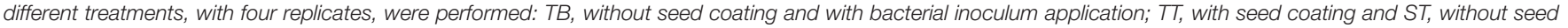
coating in a completely randomized block design.

and the TT plant populations. Sugar beet yield and quality measurement were noted at the end of the production cycle. Table 2 shows the biometric parameters reported from the three treatments (TB, ST, and TT). Both the total biomass (plant weight) and the sugar content of the beets from the TB plots were significantly higher than those for the other treatments. There were no significant differences between those values for the ST and the TT treatments, although the values of the ST treatment were somewhat higher (Table 2). Root weight and maximum beet perimeter values of the beets given the TB treatment were significantly higher than for the ST and the TT treatments, between which there was no significant variation. The highest aerial biomass and root length values were found in the beets given the TB treatment, although differences with regard to beets given the other two treatments were not significant $(p \geq 0.05)$ (Supplementary Figures 3, 4). Significant differences were found for both corrected and total sucrose content (polarization) values between TB treatment (with the lowest value) and the other two and no significant differences were found between the latter two (ST and TT) (Table 2). The results of soil parameters (edaphic characteristics), at the end of the productive cycle (upon harvest), showed no significant differences between the ST, the TT and the TB treatments.

\section{Photosynthesis Parameters Measurement}

Figure 1 shows the quantum yield of PSII (ФPSII). The beet showed significantly higher mean values (0.70) after the TB treatment than after the ST (0.64) and the TT (0.64) treatments. In relation to maximum quantum yields of photosystem II (PSII) and the non-photochemical quenching (NPQ) parameters, we observed no significant differences between either the ST, or the TT and the TB treatments (Supplementary Figures 5, 6).

\section{Determination of Resistance to Plant Pathogens}

Visual assessment revealed that the evolution of Erysiphe betae (powdery mildew) and Cercospora beticola (cercospora) infection was similar for all three treatments (Supplementary Figure 7 and Figure 2). For powdery mildew, the highest degree of infection was found on timepoint 2, although it subsequently decreased progressively. All values from timepoint 2 were above 3 points on the established 4 point-scale. The values from timepoints 1 and 3 were very similar and yet very different with respect to timepoints 2 and 4 (Supplementary Figure 7). The results for cercospora infection were similar to those for mildew, although 
TABLE 2 | Sugar beet physiological parameters measured at the end of the productive cycle.

\begin{tabular}{|c|c|c|c|}
\hline Parameters & ST & TB & TT \\
\hline Total biomass (kg) & $17.55 \pm 0.99^{a}$ & $20.35 \pm 1.47^{b}$ & $13.85 \pm 1.02^{a}$ \\
\hline $\begin{array}{l}\text { Sugar (kg/10 } \\
\text { plants) }\end{array}$ & $2.30 \pm 0.17^{a}$ & $2.73 \pm 0.22^{b}$ & $2.61 \pm 0.18^{a}$ \\
\hline $\begin{array}{l}\text { Root biomass } \\
\text { (g/plant) }\end{array}$ & $1414.17 \pm 113.71^{a}$ & $1694.17 \pm 73.14^{b}$ & $1164.17 \pm 86.77^{2}$ \\
\hline \multicolumn{4}{|l|}{ Maximum beet } \\
\hline $\begin{array}{l}\text { Perimeter } \\
\text { (cm/plant) }\end{array}$ & $44.42 \pm 1.47^{\mathrm{a}}$ & $52.02 \pm 1.35^{\mathrm{b}}$ & $41.92 \pm 1.24^{\mathrm{a}}$ \\
\hline $\begin{array}{l}\text { Polarization } \\
\text { (\%/plant) }\end{array}$ & $17.83 \pm 0.12^{\mathrm{a}}$ & $16.78 \pm 0.25^{\mathrm{b}}$ & $18.15 \pm 0.08^{a}$ \\
\hline $\begin{array}{l}\text { Corrected sucrose } \\
\text { (\%/plant) }\end{array}$ & $15.11 \pm 0.17^{a}$ & $13.79 \pm 0.28^{b}$ & $15.80 \pm 0.06^{a}$ \\
\hline $\mathrm{N}$-amino & $0.47 \pm 0.07^{a}$ & $0.63 \pm 0.11^{a}$ & $0.35 \pm 0.05^{a}$ \\
\hline Potassium, K & $5.60 \pm 0.20^{a}$ & $5.68 \pm 0.17^{a}$ & $5.05 \pm 0.13^{a}$ \\
\hline Sodium, $\mathrm{Na}$ & $1.34 \pm 0.28^{\mathrm{ab}}$ & $2.00 \pm 0.28^{a}$ & $0.85 \pm 0.11^{b}$ \\
\hline Industrial Loss\% & $15.23 \pm 0.52^{a}$ & $17.80 \pm 0.66^{b}$ & $12.92 \pm 0.34^{c}$ \\
\hline Industrial Yield\% & $84.77 \pm 0.52^{\mathrm{a}}$ & $82.20 \pm 0.66^{b}$ & $87.08 \pm 0.34^{c}$ \\
\hline
\end{tabular}

Six applications of a mixed PGPRs culture (Pseudomonas fluorescens PfO-1 and P. chlororaphis CECT 462) on the productivity of sugar beet were performed. Three different treatments, with four replicates, were performed: TB, without seed coating and with bacterial inoculum application; TT, with seed coating and ST, without seed coating in a completely randomized block design. A simple ANOVA was performed; letters show significant differences $(p \leq 0.05)$ between treatments. Values are means (10 replicates) \pm S.E.

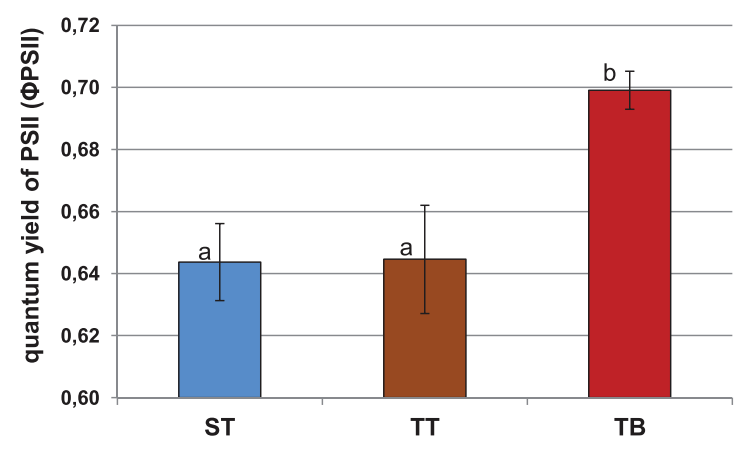

FIGURE 1 | Quantum yield of photosystem II (ФPSII) for 12-weeks-old sugar beet plants (2 days after the third PGPRs inoculation, 03 July 2018). Six applications of a mixed PGPRs culture (Pseudomonas fluorescens Pf-01 and P. chlororaphis CECT 462) on the productivity of sugar beet were performed. Three different treatments, with four replicates in a completely randomized block design, were performed: TB, without seed coating, with PGPRs inoculum application and chemical spraying; TT, with seed coating and chemical spraying and without PGPRs inoculum and ST, without seed coating, chemical spraying and PGPRs inoculum. A simple ANOVA was performed; letters show significant differences $(p \leq 0.05)$.

the values obtained over the four evaluated timepoints differed greatly between each other. All values from timepoint 2 were very near to 4 points on the established 4 point-scale. On timepoint 3 , the highest degree of cercospora infection was found in the TT treatment (3.5), whereas the values for ST and TB were 2.75 and 2.25, respectively (Figure 2). The index values for these two pathogens on timepoints 2 and 3 did not differ significantly between the three treatments (Supplementary Figures 8A,B).

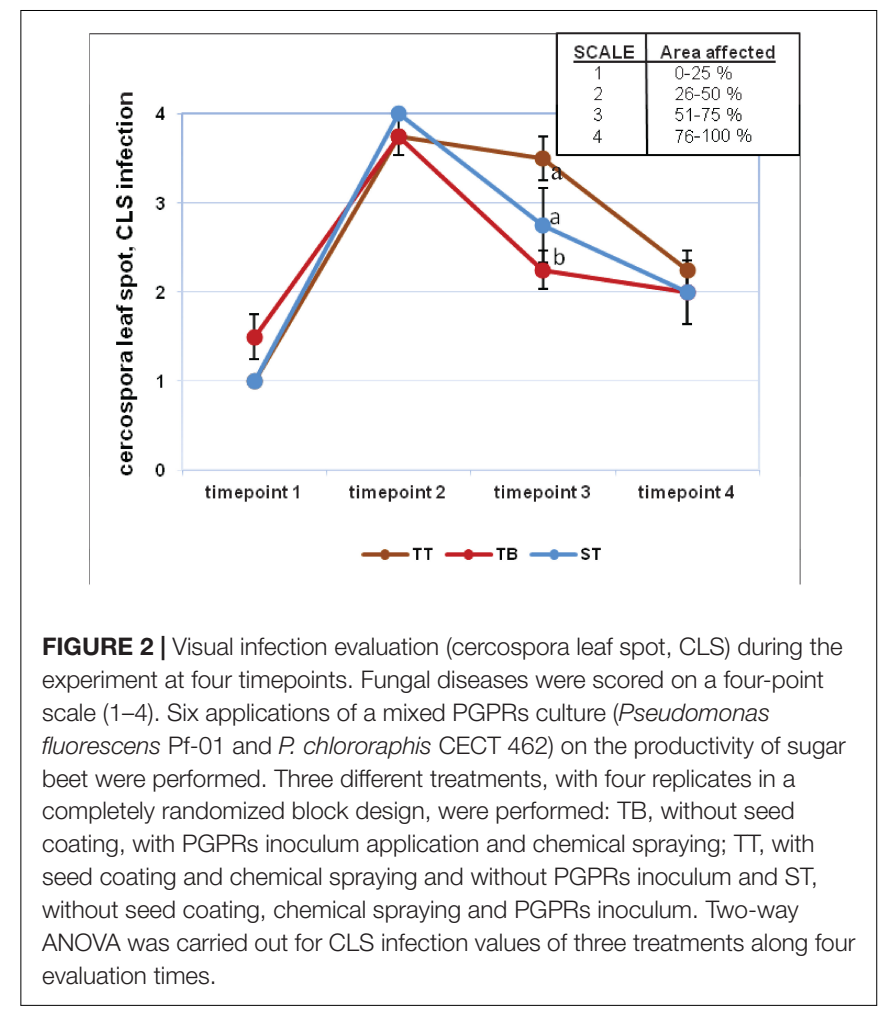

The degree of infection was higher on timepoint 2 , and this value differed significantly from that found for timepoint 3 . On timepoint 3 , the highest index for mildew infection was found for the TB treatment $(41.33 \%)$, while the ST and the TT treatments gave values of 22.31 and $12.42 \%$, respectively (Supplementary Figure 8A). In contrast, on timepoint 3 , the TT treatment had the highest cercospora infection index at $67.45 \%$, while the ST and the TB treatments had 59.37 and $56.37 \%$, respectively (Supplementary Figure 8B). The mean severity for mildew and cercospora did not differ significantly between any of the three treatments (Supplementary Figure 9), although a significant difference in the severity of these two pathogens was found for the ST treatment (Supplementary Figure 9).

\section{DISCUSSION}

The present work has studied the effect of PGPRs inoculation of sugar beet on agronomic performance, photosynthetic process changes and biocontrol effects on two main fungal pathogens.

In the 2018 campaign, the Sociedad Cooperativa General Agropecuaria (ACOR) received 3,183,974 tons of sugar beet, with a mean purity of $17.50 \%$, from the north of the region of Spain. The results of our treatments fall within the purity interval obtained by the ACOR, with values ranging between 16 and $18.4 \%$. The mean purity obtained with the PGPRs inoculation assays (TB treatment) was $16.77 \%$, a value close to that obtained by the ACOR (Table 2). The beets given the TB treatment had the highest sugar levels, total biomass, root biomass, maximum beet perimeter, $\mathrm{N}$-amino, Potassium and Sodium content values. 
In all cases, those same values following the ST treatment are at an intermediate point between those for the TB and the TT treatments (Table 2). From these results, PGPRs inoculations appear to enhance the previously discussed biometric parameters of sugar beet plants. The PGPR strains applied in the present experiment belong to Pseudomonas genus, one of the most effective phosphate solubilizing bacteria and is considered as optimal specie for their stable P-solubilizing effects (Huang et al., 2010). Therefore, this biostimulant effect could be explained by the ability of the applied PGPR strains to solubilize phosphate. This mobilization of insoluble soil phosphate into bioavailable forms that can be taken up by the plant root (Monds et al., 2006). Previous related field trials have also reported significantly increased production yields for sugar beet crops upon application of various microorganisms (Cakmakci et al., 2001). Indeed, this latter study reported increases in sugar beet root production of between 6.1 and 13\%, with an increase in sugar content of between 2.3 and $7.8 \%$, in plants inoculated with Bacillus polymyxa, Burkholderia sp. and Pseudomonas sp. From the results of our experiment, we suggest that the two assayed PGPRs triggered growth promotion in the treated sugar beet plants. This PGPRs-induced plant growth was also reported in similar studies, with plants treated with these strains growing taller and more vigorously (Suslow and Schroth, 1982; Nandakumar et al., 2001). Bakker et al. (2020) have reviewed in depth the root-associated microbiota and their functions in plant health and especially on how modern microbiomics technologies can help to decipher complex processes that govern the assembly and functioning of the root microbiome.

Nowadays, the use of photosynthetic parameters as metabolic markers of systemic induction by bacterial agents is increasing. Our results were similar to those obtained by Zou et al. (2005), who studied these variations in photosynthetic parameters. From our results, we could see that PGPRs inoculation (TB treatment) produced significant differences in the quantum yield of PSII (ФPSII) (Figure 1). This parameter indicates the real energy that the plants are using in the photochemical processes, at any given time. It seems that PGPRs inoculation could exert a beneficial effect on promoting the physiological stage of sugar beet plants, with regard to the other treatments (ST and TT). These photosynthetic modifications induced by PGPRs have been confirmed by other authors (Van Loon et al., 1998). The NPQ values for the ST, the TT and the TB treatments were also very similar, which means that the three treatments have, a priori, the same energy loss at the measurement stage (Supplementary Figure 6). Normally, NPQ reduction is observed in plants subject to different stress conditions (Whalen et al., 1991; Yamane et al., 2008). The results of the photosynthetic parameters provided evidence that PGPRs inoculation (TB treatment) showed the highest value for $\Phi$ PSII and the NPQ, the lowest value, even though the PSII was very similar in all treatments. Besides, the TT treatment showed a very low quantum yield of PSII, the highest NPQ value, and was the treatment with the highest amount of energy loss (Figure 1 and Supplementary Figure 6). The changes that occur in the photosynthetic parameters due to the use of PGPRs are not surprising because these PGPRs could be recognized as pathogen agents by plants and promote some plant-microorganisms interactions in relation to the Systemic Resistance Induced in sugar beet plants.

Although the results obtained with the biological control of cercospora and mildew were not the most successful for the TB treatment, they should nevertheless be closely analyzed, in order to design subsequent studies to perfect the application of PGPRs to sugar beet. Researchers at Montana State University (Bargabus et al., 2002, 2004) obtained a similar reduction of CLS in sugar beet plants applying a mixed microbial suspension. CLS and mildew infection indexes were higher on timepoint 2 with respect to timepoint 3 of the experiment for all the treatments (Supplementary Figure 8). In relation to the CLS infection index on timepoint 3, TB trials showed lower values than those obtained in TT and ST trials (Supplementary Figure 8B). The TB mean severity showed an intermediate value compared to the other treatments (Supplementary Figure 9). Bargabus et al. (2002, 2004) found that the application of Bacillus pumilus (strains 2036 and 203-7) and Bacillus mycoides Bac J reduced the severity of CLS in sugar beet. We could conclude that Cercospora beticola infection was slightly lower in those PGPRs inoculated plants with respect to non-treated plants (timepoint 3) (Figure 2).

Therefore, co-inoculation of PGPR strains exerts a beneficial effect on sugar beet production, in such a way that physiological modifications inside the sugar beet plants increase its agricultural productivity. Qingxiao et al. (2016) have demonstrated that $B$. velezensis $\mathrm{BAC03}$ can significantly enhance plant growth. Results showed that multiple applications of BAC03 were better than a single application in enhancing radish growth. This might be due to a combination of survival of the bacterium and prolonged period of maintaining the bacterial population at a high level by multiple applications. Similarly to our several PGPRs inoculations, in the research of Qingxiao et al. (2016), BAC03 was applied at five different timepoints during radish growth, including five days before planting (DBP), 1, 10, 20, and $30 \mathrm{DAP}$ with the same concentration of $10^{5} \mathrm{CFU} \mathrm{\textrm {cm } ^ { 3 }}$ potting mix. Fresh and dry weight of leaves and roots were determined at harvest, 6 weeks after planting. Similar to our Pseudomonas inoculation, sugar beet seeds were treated with the mix bacterial suspensions for $30 \mathrm{~min}$ and also during sowing (Fikrettin et al., 2004).

Hence, PGPR efficacy depends on several factors, but it is assessed according to the specific PGPR strains that are used, the amount of inoculum $(\mathrm{CFU} / \mathrm{ml})$ and the plant inoculation method. As Munees and Mohammad (2011) indicated, the use of PGPR to augment crop productivity has been limited largely due to the variability and inconsistency of results observed under laboratory, greenhouse and field trials. Soil is an unpredictable environment and an intended result is sometimes difficult to achieve. Climatic variations has also a large impact on the effectiveness of PGPR but sometimes unfavorable growth conditions in the field are to be expected as a normal functioning of agriculture (Zaidi et al., 2009). Despite all these factors, there are many studies that prove the increase in crop yields following PGPR applications in the growth chambers and field trials (Munees and Mohammad, 2011).

The two assayed PGPR strains, Pseudomonas fluorescens Pf0-1 and Pseudomonas chlororaphis CECT 462, triggered a 
significant increase in sugar beet production yield and quality. Our results have shown that, on the whole, the beneficial effects of PGPRs are directly observable. There were increases of sugar beet physiological and photosynthetic parameters. Indirectly, PGPRs co-inoculation did not exert a desirable biocontrol against powdery mildew and cercospora infections.

Finally, PGPRs inoculation techniques used with different crops can be complemented with more traditional agricultural techniques, as far as may be required to ensure sustainable agricultural production.

\section{DATA AVAILABILITY STATEMENT}

The original contributions presented in the study are included in the article/Supplementary Material, further inquiries can be directed to the corresponding author/s.

\section{AUTHOR CONTRIBUTIONS}

All authors listed have made a substantial, direct and intellectual contribution to the work, and approved it for publication.

\section{FUNDING}

This research has contributed to H2020 Project "Integrated Novel Strategies for Reducing the Use and Impact of Pesticides, Toward Sustainable Mediterranean Vineyards and Olive Groves" (Project NOVATERRA, Commission's Horizon 2020, Grant Agreement no. 101000554).

\section{ACKNOWLEDGMENTS}

We would like to express our thanks to Koipesol SEMILLAS, S.A. for the generous supply of the seeds; to Sociedad Cooperativa General Agropecuaria, ACOR for technical collaboration, especially to J. Redondo; our thanks also goes to L.M. Palencia, J.M. Palencia, E.M. García-Martínez, and M. Miranda for their generous collaboration in the field assays; and to D. Pérez-Alonso, from the University of Burgos for their technical collaboration.

\section{SUPPLEMENTARY MATERIAL}

The Supplementary Material for this article can be found online at: https://www.frontiersin.org/articles/10.3389/fpls.2020. 604898/full\#supplementary-material

Supplementary Figure 1 | Timelines for ST, TB and TT treatments. Six applications of a mixed PGPRs culture (Pseudomonas fluorescens Pf-01 and $P$. chlororaphis CECT 462) on the productivity of sugar beet were performed. Three different treatments, with four replicates in a completely randomized block design, were performed: TB, without seed coating, with PGPRs inoculum application and chemical spraying; $\Pi$, with seed coating and chemical spraying and without PGPRs inoculum and ST, without seed coating, chemical spraying and PGPRs inoculum.
Supplementary Figure 2 | Evaluation of the incidence of (A) Cercospora Leaf Spot, CLS and (B) Powdery Mildew throughout the productive cycle of sugar beet. The fungal incidences of both pathogens were scored on a four-point scale. For the assessment of fungal incidences, the following parameters were recorded: for CLS incidence, extent of necrotic leaf area with characteristic brown round and necrotic spots and for Powdery Mildew, extent of white dust-like mycelium on leaf surface. Both fungal incidences were rated on a 1-4 scale according to the extent of the affected leaf area (1: between 0 and 25\%, 2: between 26 and 50\%, 3: between 51 and $75 \%$ and 4: between 76 and 100\%).

Supplementary Figure $\mathbf{3}$ | Aerial biomass measured at the end of the sugar beet productive cycle. Six applications of a mixed PGPRs culture (Pseudomonas fluorescens Pf-01 and P. chlororaphis CECT 462) on the productivity of sugar beet were performed. Three different treatments, with four replicates in a completely randomized block design, were performed: TB, without seed coating, with PGPRs inoculum application and chemical spraying; $\Pi$, with seed coating and chemical spraying and without PGPRs inoculum and ST, without seed coating, chemical spraying and PGPRs inoculum. A simple ANOVA was performed; letters show significant differences $(p \leq 0.05)$.

Supplementary Figure 4 | Root length measured at the end of the sugar beet productive cycle. Six applications of a mixed PGPRs culture (Pseudomonas fluorescens Pf-01 and P. chlororaphis CECT 462) on the productivity of sugar beet were performed. Three different treatments, with four replicates in a completely randomized block design, were performed: TB, without seed coating, with PGPRs inoculum application and chemical spraying; $\Pi$, with seed coating and chemical spraying and without PGPRs inoculum and ST, without seed coating, chemical spraying and PGPRs inoculum. A simple ANOVA was performed; letters show significant differences $(p \leq 0.05)$.

Supplementary Figure 5 | Maximum quantum yield of photosystem II (PSII) calculated as Fv/Fm for 12-weeks-old sugar beet plants (2 days after the third PGPRs inoculation, 03 July 2018).Three different treatments, with four replicates in a completely randomized block design, were performed: TB, without seed coating, with PGPRs inoculum application and chemical spraying; $\Pi$, with seed coating and chemical spraying and without PGPRs inoculum and ST, without seed coating, chemical spraying and PGPRs inoculum. A simple ANOVA was performed; letters show significant differences $(p \leq 0.05)$.

Supplementary Figure 6 | Non-photochemical quenching (NPQ) for 12-weeks-old sugar beet plants (2 days after the third PGPRs inoculation, 03 July 2018). Three different treatments, with four replicates in a completely randomized block design, were performed: TB, without seed coating, with PGPRs inoculum application and chemical spraying; $\Pi$, with seed coating and chemical spraying and without PGPRs inoculum and ST, without seed coating, chemical spraying and PGPRs inoculum. A simple ANOVA was performed; letters show significant differences $(p \leq 0.05)$.

Supplementary Figure 7 | Visual infection evaluation (powdery mildew) during the experiment at four timepoints. Six applications of a mixed PGPRs culture (Pseudomonas fluorescens Pf-01 and P. chlororaphis CECT 462) on the productivity of sugar beet were performed. Three different treatments, with four replicates in a completely randomized block design, were performed: TB, without seed coating, with PGPRs inoculum application and chemical spraying; TT, with seed coating and chemical spraying and without PGPRs inoculum and ST, without seed coating, chemical spraying and PGPRs inoculum. Two-way ANOVA was performed; letters show significant differences $(p \leq 0.05)$. ST, TB, and TT treatments showed no significant differences (same letters are not shown).

Supplementary Figure 8 | Evaluation of the infection index, (a) powdery mildew and (b) cercospora leaf spot, CLS on timepoints 2 and 3 of the experiment. Six applications of a mixed PGPRs culture (Pseudomonas fluorescens Pf-01 and P. chlororaphis CECT 462) on the productivity of sugar beet were performed. Three different treatments, with four replicates in a completely randomized block design, were performed: TB, without seed coating, with PGPRs inoculum application and chemical spraying; $\Pi$, with seed coating and chemical spraying and without PGPRs inoculum and ST, without seed coating, chemical spraying and PGPRs inoculum. A simple ANOVA was performed; different capital letters for treatments and lowercase letters for time show significant differences $(p \leq 0.05)$. In CLS infection, ST, TB and TT treatments showed no significant differences (same letters are not shown). Vertical error bars are S.E.D. 
Supplementary Figure 9 | Evaluation of the severity of infection of powdery mildew and cercospora leaf spot (CLS) on timepoint two of the experiment. Six applications of a mixed PGPRs culture (Pseudomonas fluorescens Pf-01 and $P$. chlororaphis CECT 462) on the productivity of sugar beet were performed. Three different treatments, with four replicates in a completely randomized block design, were performed: TB, without seed coating, with PGPRs inoculum

\section{REFERENCES}

Agaras, B. C., Noguera, F., González Anta, G., Wall, L., and Valverde, C. (2020). Biocontrol potential index of pseudomonads, instead of their direct-growth promotion traits, is a predictor of seed inoculation effect on crop productivity under field conditions. Biol. Control. 143:104209. doi: 10.1016/j.biocontrol. 2020.104209

Backer, R., Rokem, J. S., Ilangumaran, G., Lamont, J., Praslickova, D., Ricci, E., et al. (2018). Plant growth-promoting rhizobacteria: context, mechanisms of action, and roadmap to commercialization of biostimulants for sustainable agriculture. Front. Plant Sci. 9:1473. doi: 10.3389/fpls.2018.01473

Baker, N. R. (2008). Chlorophyll fluorescence: a probe of photosynthesis in vivo. Annu. Rev. Plant Biol. 59, 89-113. doi: 10.1146/annurev.arplant.59.032607. 092759

Bakker, P. A. H. M., Berendsen, R. L., Doornbos, R. F., Wintermans, P. C. A., and Pieterse, C. M. J. (2013). The rhizosphere revisited: root microbiomics. Front. Plant Sci. 4:165. doi: 10.3389/fpls.2013.00165

Bakker, P. A. H. M., Berendsen, R. L., Van Pelt, J. A., Vismans, G., Yu, K., Li, E., et al. (2020). The soil-borne identity and microbiome-assisted agriculture: looking back to the future. Mol. Plant 13, 1394-1401. doi: 10.1016/j.molp.2020.09.017

Bargabus, R. L., Zidack, N. K., Sherwood, J. W., and Jacobsen, B. J. (2002). Characterization of systemic resistance in sugar beet elicited by a nonpathogenic, phyllosphere-colonizing Bacillus mycoides, biological control agent. Physiol. Mol. Plant Pathol. 61, 289-298. doi: 10.1006/pmpp.2003.0443

Bargabus, R. L., Zidack, N. K., Sherwood, J. W., and Jacobsen, B. J. (2004). Screening for the identification of potential biological control agents that induce systemic acquired resistance in sugar beet. Biol. Control 30, 342-350. doi: 10.1016/j.biocontrol.2003.11.005

Berendsen, R. L., Pieterse, C. M. J., and Bakker, P. A. H. M. (2012). The rhizosphere microbiome and plant health. Trends Plant Sci. 17, 478-486. doi: 10.1016/j. tplants.2012.04.001

Berger, S., Papadopoulos, M., Schreiber, U., Kaiser, W., and Roitsch, T. (2004). Complex regulation of gene expression, photosynthesis and sugar levels by pathogen infection in tomato. Physiol. Plant 122, 419-428. doi: 10.1111/j.13993054.2004.00433.x

Cakmakci, R., Kantar, F., and Sahin, F. (2001). Effect of $\mathrm{N}_{2}$-fixing bacterial inoculations on yield of sugar beet and barley. J. Plant Nutr. Soil Sci. 164, 527-531. doi: 10.1002/1522-2624(200110)164:5<527::aid-jpln527>3.0.co;2- 1

CECT - Colección Española de Cultivos Tipo (2020). Universidad de Valencia, Spain. Available online at https://www.uv.es/uvweb/coleccionespanola-cultivos-tipo/es/catalogo-cepas/medios-cultivo/buscador-cepas1285892802374.html (accessed July 7, 2020).

Compant, S., Duffy, B., Nowak, J., Clément, C., and Barka, E. A. (2005). Use of plant growth-promoting bacteria for biocontrol of plant diseases: principles, mechanisms of action, and future prospects. Appl. Environ. Microbiol. 71, 4951-4959. doi: 10.1128/aem.71.9.4951-4959.2005

Doberein, J., and Campelo, A. B. (1971). Non-symbiotic nitrogen fixing bacteria in tropical soils. Plant Soil 35, 457-470. doi: 10.1007/bf02661871

Dohm, J. C., Minoche, A. E., Holtgräwe, D., Capella-Gutiérrez, S., Zakrzewski, F., Tafer, H., et al. (2014). The genome of the recently domesticated crop plant sugar beet (Beta vulgaris). Nature 505, 546-549. doi: 10.1038/nature 12817

Esteban Baselga, J. A. (1993). La remolacha azucarera en Castilla y León. Agricul. Rev. Agropecu. 732, 604-610.

FAOSTAT (2019). Crops - Production/Yield Quantities of Sugar Beet. Available online at: http://www.fao.org/faostat/en/\#data/QC (accessed October 30, 2020)

Fernández-Aparicio, M., Prats, E., Emeran, A. A., and Rubiales, D. (2009). Characterization of resistance mechanisms to powdery mildew (Erysiphe betae) in beet (Beta vulgaris). Phytopathology 99, 385-389. doi: 10.1094/phyto-99-40385 application and chemical spraying; $\Pi$, with seed coating and chemical spraying and without PGPRs inoculum and ST, without seed coating, chemical spraying and PGPRs inoculum. A simple ANOVA was performed between treatments; asterisk indicates significant differences between treatments $(p \leq 0.05)$. In powdery mildew, ST, TB, and TT treatments did not shown significant differences (same letters are not shown). Vertical error bars are S.E.D.

Fikrettin, S., Çakmakçi, R., and Kantar, F. (2004). Sugar beet and barley yields in relation to inoculation with N2-fixing and phosphate solubilizing bacteria. Plant Soil 265, 123-129. doi: 10.1007/s11104-005-0334-8

Genty, B., Briantais, J. M., and Baker, R. N. (1989). The relationship between the quantum yield of photosynthetic electron transport and quenching of chlorophyll fluorescence. Biochim. Biophys. Acta 990, 87-92. doi: 10.1016/ s0304-4165(89)80016-9

Gyaneshwar, P., Kumar, G. N., Parekh, L. J., and Poole, P. S. (2002). Role of soil microorganisms in improving P nutrition of plants. Plant Soil 245, 83-93.

Hassani, M. A., Durán, P., and Hacquard, S. (2018). Microbial interactions within the plant holobiont. Microbiome 6:58.

Heick, T. M., Hansen, A. L., Munk, L., Labouriau, R., Wu, K., and Jørgensen, L. N. (2020). The effect of fungicide sprays on powdery mildew and rust and yield of sugar beet in Denmark. Crop Prot. 135:105199. doi: 10.1016/j.cropro.2020. 105199

Hiltner, L. (1904). Über neuere Erfahrungen und Probleme auf dem Gebiete der bodenbakteriologie unter besonderer berücksichtigung der gründüngung und brache. Arb. der Dtsch. Lanwirtschaftlichen Gesellschaft 98, 59-78.

Huang, J., Sheng, X., and He, L. (2010). Biodiversity of phosphate-dissolving and plant growth promoting endophytic bacteria of two crops. Acta Microbiol. Sinica 50, 710-716.

ITACYL - Instituto Tecnológico Agrario de Castilla y León (2019). Consejería de Agricultura y Ganadería, Junta de Castilla y León. Available online at: http: //www.atlas.itacyl.es/visor (accessed November 5, 2020).

IUSS Working Group WRB (2015). World Reference Base for Soil Resources 2014, update 2015 International Soil Classification System for Naming Soils and Creating Legends for Soil Maps. World Soil Resources Reports No. 106. Rome: FAO.

Jay, S., Comar, A., Benicio, R., Beauvois, J., Dutartre, D., Daubige, G., et al. (2020). Scoring cercospora leaf spot on sugar beet: comparison of UGV and UAV phenotyping systems. Plant Phenom. 2020:9452123, 1-18.

Kamou, N. N., Cazorla, F., Kandylas, G., and Lagopodi, A. L. (2020). Induction of defense-related genes in tomato plants after treatments with the biocontrol agents Pseudomonas chlororaphis ToZa7 and Clonostachys rosea IK726. Arch. Microbiol. 202, 257-267. doi: 10.1007/s00203-019-01739-4

Khan, M., Smith, L., Bredehoeft, M., Roehl, S., and Fischer, J. (2001). Cercospora Leaf Spot Control in Eastern North Dakota and Minnesota in 2000, Sugar Beet Research and Extension Report. Fargo, ND: North Dakota State University \& University of Minnesota.

Kloepper, J. W., Leong, J., Teintze, M., and Schroth, M. N. (1980). Enhanced plant growth by siderophores produced by plant growth-promoting rhizobacteria. Nature 286, 885-886. doi: 10.1038/286885a0

Krause, G. H., and Weis, E. (1991). Chlorophyll fluorescence and photosynthesis: the basics. Annu. Rev. Plant Phys. 42, 313-349.

Kumar, A., Patelc, J. S., Meenad, V. S., and Ramtekee, P. W. (2019). Plant growth-promoting rhizobacteria: strategies to improve abiotic stresses under sustainable agriculture. J. Plant Nutr. 42, 1402-1415. doi: 10.1080/01904167. 2019.1616757

Kusstatscher, P., Cernava, T., Harms, K., Maier, J., Eigner, H., Berg, G., et al. (2019a). Disease incidence in sugar beet fields is correlated with microbial diversity and distinct biological markers. Phytobiomes J. 3, 22-30. doi: 10.1094/ pbiomes-01-19-0008-r

Kusstatscher, P., Zachow, C., Harms, K., Maier, J., Eigner, H., Berg, G., et al. (2019b). Microbiome-driven identification of microbial indicators for postharvest diseases of sugar beets. Microbiome 7:112.

Levall, M. W., and Bornman, J. F. (2000). Differential response of a sensitive and tolerant sugarbeet line to Cercospora beticola infection and UV-B radiation. Physiol. Plant 109, 21-27. doi: 10.1034/j.1399-3054.2000.100104.x

MAPA. (1994). Métodos Oficiales de Análisis, : Suelos y Aguas, Vol. 3. Madrid: MAPA. 
Mendes, R., Kruijt, M., de Bruijn, I., Dekkers, E., van der Voort, M., Schneider, J. H. M., et al. (2011). Deciphering the rhizosphere microbiome for disease suppressive bacteria. Science 332, 1097-1100. doi: 10.1126/science.1203980

Mia, M. A. B., Shamsuddin, Z. H., and Mahmood, M. (2010). Use of plant growth promoting bacteria in banana: a new insight for sustainable banana production. Int. J. Agric. Biol. 12, 459-467.

Monds, R. D., Newell, P. D., Schwartzman, J. A., and O’Toole, G. A. (2006). Conservation of the Pho regulon in Pseudomonas fluorescens Pf0-1. Appl. Environ. Microbiol. 72, 1910-1924. doi: 10.1128/aem.72.3.1910-1924.2006

Munees, A., and Mohammad, S. K. (2011). Functional aspects of plant growth promoting rhizobacteria: recent advancements. Insight Microbiol. 1, 39-54. doi: 10.5567/imicro-ik.2011.39.54

Nandakumar, R., Viswanathan, R., Babu, S., Shella, J., Raghuchander, T., and Samiyappan, R. (2001). A new bio-formulation containing plant growth promoting rhizobacterial mixture for the management of sheath blight and enhanced grain yield in rice. Biocontrol 46, 493-510.

Naureen, Z., Price, A. H., Hafeez, F., and Roberts, M. R. (2009). Identification of rice blast disease-suppressing bacterial strains from the rhizosphere of rice grown in Pakistan. Crop Prot. 28, 1052-1060. doi: 10.1016/j.cropro.2009.08.007

Niu, X., Song, L., Xiao, Y., and Ge, W. (2018). Drought-tolerant plant growthpromoting rhizobacteria associated with foxtail millet in a semi-arid and their potential in alleviating drought stress. Front. Microbiol. 8:2580.

OECD/FAO (2020). "Table C.3 - world sugar projections," in OECD-FAO Agricultural Outlook 2020-2029, (Paris: OECD Publishing). Available online at: https://www.oecd-ilibrary.org/agriculture-and-food/world-sugarprojections_b62e023c-en (accessed June 23, 2020).

Ögren, E., and Baker, N. R. (1985). Evaluation of a technique for the measurement of chlorophyll fluorescence from leaves exposed to continuous white light. Plant Cell Environ. 8, 539-547. doi: 10.1111/j.1365-3040.1985.tb01691.x

Oku, S., Komatsu, A., Tajima, T., Nakashimada, Y., and Kato, J. (2012). Identification of chemotaxis sensory proteins for amino acids in Pseudomonas fluorescens $\mathrm{Pf} 0-1$ and their involvement in chemotaxis to tomato root exudate and root colonization. Microbes Environ. 27, 462-469. doi: 10.1264/jsme2. me12005

Pan, L., Zhu, O., Lu, R., and McGrath, J. M. (2015). Determination of sucrose content in sugar beet by portable visible and near-infrared spectroscopy. Food Chem. 167, 264-271. doi: 10.1016/j.foodchem.2014.06.117

Penrose, D. M., Moffatt, B. A., and Glick, B. R. (2001). Determination of 1aminocycopropane-1-carboxylic acid (ACC) to assess the effects of ACC deaminase-containing bacteria on roots of canola seedlings. Can. J. Microbiol. 47, 77-80. doi: 10.1139/w00-128

Pooja, K., Krishna, K. C., Akhileshwar, K. S., and Amit, K. S. (2019). "PGPR bioelicitors: induced systemic resistance (ISR) and proteomic perspective on biocontrol," in PGPR Amelioration in Sustainable Agriculture -Food Security and Environmental Management, eds K. S. Amit, K. Ajay, and K. S. Pawan (Cambridge: Woodhead Publishing), 67-84. doi: 10.1016/b978-0-12-8158791.00004-5

Qingxiao, M., Helen, J., and Jianjun, H. (2016). Effects of Bacillus velezensis strain BAC03 in promoting plant growth. Biol. Control 98, 18-26. doi: 10.1016/j. biocontrol.2016.03.010

Raaijmakers, J. M., and Mazzola, M. (2016). Soil immune responses. Science 352, 1392-1394. doi: 10.1126/science.aaf3252

Robert, C., Bancal, M. O., Lannou, C., and Ney, B. (2006). Quantification of the effects of Septoria tritici blotch on wheat leaf gas exchange with respect to lesion age, leaf number, and leaf nitrogen status. J. Exp. Bot. 57, 225-234.

Rodríguez-Moreno, L., Pineda, M., Soukupová, J., Macho, A. P., Beuzón, C. R., Barón, M., et al. (2008). Early detection of bean infection by Pseudomonas syringae in asymptomatic leaf areas using chlorophyll fluorescence imaging. Photosynth. Res. 96, 27-35. doi: 10.1007/s11120-007-9278-6

Sacristán Pérez-Minayo, G., Reguera-Useros, J. I., López-Robles, D. J., GarcíaVillaraco, A., and Gutiérrez-Mañero, F. J. (2011). Evaluation of biocontrol agrotechniques against $R$. solani: study of microbial communities catabolic profile modifications. J. Agric. Sci. 149, 595-607. doi: 10.1017/s0021859611000025

Santiago, C. D., Yagi, S., Ijima, M., Nashimoto, T., Sawada, M., Ikeda, S., et al. (2017). Bacterial compatibility in combined inoculations enhances the growth of potato seedlings. Microbes Environ. 32, 14-23. doi: 10.1264/jsme2.me 16127

Santner, A., Calderon-Villalobos, L. I. A., and Estelle, M. (2009). Plant hormones are versatile chemical regulators of plant growth. Nat. Chem. Biol. 5, 301-307. doi: $10.1038 /$ nchembio. 165
Scher, F. M., and Baker, R. (1982). Effect of Pseudomonas putida and a synthetic iron chelator on induction of soil suppressiveness to Fusarium wilt pathogens. Phytopathology 72, 1567-1573. doi: 10.1094/phyto-72-1567

Stanek, V., and Pavlas, P. (1934). Über eine schnelle, informative methode zur bestimmung des schädlichen stickstoffes, der amide und der aminosäuren in der rübe. Zuckerindustrie Czechoslov. Republic 59, 129-142.

Stringlis, I., Zhang, H., Pieterse, C., Bolton, M., and de Jonge, R. (2018). Microbial small molecules - weapons of plant subversion. Nat. Prod. Rep. 35, 410-433. doi: $10.1039 / \mathrm{c} 7 \mathrm{np} 00062 \mathrm{f}$

Suslow, T. V., and Schroth, M. N. (1982). Rhizobacteria of sugar beets: effects of seed application and root colonization on yield. Phytopathology 72, 199-206. doi: 10.1094/phyto-72-199

Van Loon, L. C., Bakker, P. A. H. M., and Pieterse, C. M. J. (1998). Systemic resistance induced by rhizosphere bacteria. Annu. Rev. Phytopathol. 36, 453483. doi: 10.1146/annurev.phyto.36.1.453

Van Zwieten, L., Rust, J., Kingston, T., Merrington, G., and Morris, S. (2004). "Influence of copper fungicide residues on occurrence of earthworms in avocado orchard soils. Sci. Total Environ. 329, 29-41. doi: 10.1016/j.scitotenv. 2004.02.014

Weijuan, H., Donglei, S., Jiantao, F., Huanhuan, Z., Ronghua, W., and Yuxing, A. (2020). Effects of continuous sugar beet cropping on rhizospheric microbial communities. Genes 11:13. doi: 10.3390/genes11010013

Whalen, M. C., Innes, R. W., Bent, A. F., and Staskawicz, B. J. (1991). Identification of Pseudomonas syringae pathogens of Arabidopsis and a bacterial locus determining avirulence on both Arabidopsis and soybean. Plant Cell 3, 49-59. doi: $10.2307 / 3869199$

Wieninger, L., and Kubadinow, N. (1973). Die Stickstoffdüngung und ihre auswirkungen auf technologische qualitätsmerkrnale der zuckerrübe. Zucker 26, 65-70.

Wolfgang, A., Zachow, C., Müller, H., Grand, A., Temme, N., Tilcher, R., et al. (2020). Understanding the impact of cultivar, seed origin, and substrate on bacterial diversity of the sugar beet rhizosphere and suppression of soil-borne pathogens. Front. Plant Sci. 11:560869. doi: 10.3389/fpls.2020.560869

Würschum, T., Reif, J. C., Kraft, T., Janssen, G., and Zhao, Y. (2013). Genomic selection in sugar beet breeding populations. BMC Genet. 14:85. doi: 10.1186/ 1471-2156-14-85

Yamane, K., Kawasaki, M., Taniguchi, M., and Miyake, H. (2008). Correlation between chloroplast ultrastructure and chlorophyll fluorescence characteristics in the leaves of rice (Oryza sativa L.) grown under salinity. Plant Prod. Sci. 11, 139-145. doi: 10.1626/pps.11.139

Yang, S. F., and Hoffman, N. E. (1984). Ethylene biosynthesis and its regulation in higher plants. Annu. Rev. Plant Physiol. Plant Mol. Biol. 35, 155-189. doi: 10.1146/annurev.pp.35.060184.001103

Zachow, C., Fatehi, J., Cardinale, M., Tilcher, R., and Berg, G. (2010). Strain specific colonization pattern of Rhizoctonia antagonists in the root system of sugar beet. FEMS Microbiol. Ecol. 74, 124-135. doi: 10.1111/j.1574-6941.2010.00930.x

Zachow, C., Tilcher, R., and Berg, G. (2008). Sugar beet-associated bacterial and fungal communities show a high indigenous antagonistic potential against plant pathogens. Microb. Ecol. 55, 119-129. doi: 10.1007/s00248-007-9257-7

Zaidi, A., Khan, M. S., Ahemad, M., and Oves, M. (2009). Plant growth promotion by phosphate solubilizing bacteria. Acta Microbiol. Immunol. Hung. 56, 263284. doi: 10.1556/amicr.56.2009.3.6

Zou, J., Rodriguez-Zas, S., Aldea, M., Li, M., Zhu, J., Gonzalez, D., et al. (2005). Expression profiling soybean response to Pseudomonas syringae reveals new defence-related genes and rapid HR specific downregulation of photosynthesis. Mol. Plant Microbe Interact. 18, 1161-1174. doi: 10.1094/mpmi-18-1161

Conflict of Interest: LM-B was employed by the company Syngenta.

The remaining authors declare that the research was conducted in the absence of any commercial or financial relationships that could be construed as a potential conflict of interest.

Copyright (C) 2020 Sacristán-Pérez-Minayo, López-Robles, Rad and MirandaBarroso. This is an open-access article distributed under the terms of the Creative Commons Attribution License (CC BY). The use, distribution or reproduction in other forums is permitted, provided the original author(s) and the copyright owner(s) are credited and that the original publication in this journal is cited, in accordance with accepted academic practice. No use, distribution or reproduction is permitted which does not comply with these terms. 